\title{
O uso de creatina monohidratada e o possível compromentimento na disfunção renal: revisão narrativa
}

\author{
Use of creatine monohydrate and the possible impairment in renal dysfunction: a narrative review \\ El uso de creatina monohidrato y el posible deterioro de la disfunción renal: una revisión narrativa \\ Leandro Colombo Cassiano¹, Faisson Luís Leal Feitosa1, Victor Jorge Lago ${ }^{1}$, Silvio de Almeida \\ Junior ${ }^{1}$, Fabíola Pansani Maniglia ${ }^{1}$, Gabriel Silveira Franco ${ }^{1 *}$.
}

\section{RESUMO}

Objetivo: Revisar a relação entre a suplementação de creatina, especialmente em sua forma monohidratada, e o declínio da função renal, bem como se há uma relação entre essa suplementação e a lesão renal. Revisão bibliográfica: Os achados de lesão renal associada ao uso de creatina não puderam atribuir o quadro clínico de forma isolada ao uso da substância. Deve-se considerar que as características individuais, bem como do consumo alimentar e das demais suplementações, exercem papel importante. $O$ uso de creatina em doses recomendadas tem sua segurança garantida pelos órgãos regulamentadores e não há, até o momento, contraindicação para o seu uso por pessoas saudáveis e que apresentem necessidade de suplementação. Considerações finais: Ao analisar o uso da creatina isoladamente e como único fator desencadeante para a injúria renal, não foram encontradas evidências suficientes que consolidem a associação entre disfunção renal e o uso desta substância. $O$ uso da creatina é seguro por pessoas saudáveis, quando em doses adequadas.

Palavras-chave: Nefropatias, Insuficiência renal, Creatina, Suplementos nutricionais.

\begin{abstract}
Objective: Review the relationship between creatine supplementation, especially in its monohydrate form, and the decline in renal function, as well as whether there is a relationship between this supplementation and kidney injury. Bibliographic review: The findings of renal injury associated with the use of creatine could not attribute the clinical picture in isolation to the use of the substance. It should be considered that individual characteristics, as well as food consumption and other supplements, play an important role. The use of creatine in recommended doses has its safety guaranteed by regulatory agencies and there is no contraindication for its use by healthy people and those in need of supplementation so far. Final considerations: When analyzing the use of creatine alone and as the only triggering factor for kidney injury, insufficient evidence was found to consolidate the association between kidney dysfunction and the use of this substance. The use of creatine is safe for healthy people, when in adequate doses.
\end{abstract}

Keywords: Kidney diseases, Renal insufficiency, Creatine, Dietary supplements.

${ }^{1}$ Universidade de Franca (UNIFRAN), Franca - SP. *E-mail: gabriel_franco85@hotmail.com

Coordenação de Aperfeiçoamento de Pessoal de Nível Superior (CAPES), Código de Financiamento 001 (88887.479355/2020-00).

SUBMETIDO EM: 8/2021

ACEITO EM: 8/2021

PUBLICADO EM: 8/2021 


\section{RESUMEN}

Objetivo: Revise la relación entre la suplementación con creatina, especialmente en su forma monohidrato, y la disminución de la función renal, así como si existe una relación entre esta suplementación y la lesión renal. Revisión bibliográfica: Los hallazgos de lesión renal asociados con el uso de creatina no pudieron atribuir el cuadro clínico de forma aislada al uso de la sustancia. Se debe considerar que las características individuales, así como el consumo de alimentos y otros complementos, juegan un papel importante. El uso de creatina en las dosis recomendadas tiene su seguridad garantizada por las agencias reguladoras y hasta el momento no existe contraindicación para su uso por personas sanas y que necesitan suplementos. Consideraciones finales: Al analizar el uso de creatina sola y como único factor desencadenante de daño renal, no se encontró evidencia suficiente para consolidar la asociación entre disfunción renal y uso de esta sustancia. El uso de creatina es seguro para personas sanas, cuando se administra en dosis adecuadas.

Palabras clave: Enfermedades renales, Insuficiencia renal, Creatina, Suplementos dietéticos.

\section{INTRODUÇÃO}

A creatina é uma molécula composta por três aminoácidos: arginina, glicina e metionina, sendo uma das oito substâncias derivadas da guanidina em suas formas fosforiladas. É uma amina sintetizada naturalmente pelo pâncreas, fígado e rins sendo também obtida por determinados alimentos e tendo suas maiores concentrações no músculo esquelético e em menor quantidade no músculo cardíaco, músculo liso, cérebro, rins e espermatozoides. É utilizada como recurso ergogênico dietético desde seu comprovado aumento da creatina muscular e os achados na literatura mostram ainda que pode promover maior desempenho e ganho de massa magra e força (FALCÃO LEM, 2016; OLIVEIRA LM, 2017).

Cerca de $40 \%$ da quantidade armazenada no músculo permanece como creatina e $60 \%$ torna-se fosfocreatina $(\mathrm{PCr})$, sendo que essa forma fica retida no músculo e servindo posteriormente como reservatório, que poderá ser utilizado de acordo com a demanda energética. No músculo esquelético ocorre uma reação envolvendo a adenosina trifosfato (ATP) com a creatina por meio da enzima creatina quinase, gerando adenosina difosfato (ADP) e PCr, como por exemplo quando o ATP ou pH intramuscular diminuem, o que leva à formação de mais ATP a partir da PCr. A PCr e creatina atuam também com efeitos antioxidantes e mecânicos na proteção celular, por exemplo em células nervosas e em eritrócitos (VEJA J e HUIDOBRO EJP, 2019).

Em termos de equivalência alimentar, a suplementação com $5 \mathrm{~g}$ de creatina corresponde a $1,1 \mathrm{~kg}$ de carne. Estudiosos sugerem que quando ingerida nesta quantidade, de quatro a seis vezes ao dia por dois ou mais dias, observa-se um aumento de sua quantidade basal intramuscular em até $50 \%$ em alguns indivíduos. Mas vale ressaltar que o consumo superior a $5 \mathrm{~g} /$ dia não é aconselhável devido à carência de pesquisas que afirmem sua segurança a longo prazo em quantidades acima dessa dose (VEJA $\mathrm{J}$ e HUIDOBRO EJP, 2019; LIMA CLS, et al., 2020).

A creatina é excretada sob a forma de creatinina por meio da urina a uma taxa de aproximadamente $2 \mathrm{~g} /$ dia. É filtrada nos rins, não havendo reabsorção para o sangue e desse modo a concentração de creatinina no plasma é reflexo da filtração renal. Os valores de referência da creatinina são: crianças de $1 \mathrm{a}$ 5 anos: $0,3-0,5 \mathrm{mg} / \mathrm{dL}$, crianças de 5 a 10 anos: $0,5-0,8 \mathrm{mg} / \mathrm{dL}$, adultos do sexo masculino: $0,7-1,2 \mathrm{mg} / \mathrm{dL}$ e adultos do sexo feminino: $0,5-1,1 \mathrm{mg} / \mathrm{dL}$. Quantidades abaixo da normalidade podem indicar insuficiência hepática, miopatia e doenças de debilitação muscular. Já os níveis acima da normalidade podem revelar fluxo renal reduzido, hipotensão, desidratação, doenças renais, obstruções renais, síndrome hepato-renal e dano muscular (VEJA J e HUIDOBRO EJP, 2019; FLORENTIN AN et al., 2021).

Ressalta-se que, além do aumento de força e colaboração para ganho de massa magra, a suplementação também apresenta melhoras significativas em doenças crônico-degenerativas, comprometimentos neuromusculares e tolerância à glicose (FALCÃO LEM, 2016). Além da cafeína, a 
creatina é a única substância ergogênica reconhecida pelo Escritório Federal de Saúde Pública Suíço (BAG) e pela Autoridade Europeia para a Segurança dos Alimentos (EFSA) como eficaz e segura quando utilizadas doses de 3 a 4g/dia (WALLIMANN T, et al., 2017).

A suplementação com creatina permanece estigmatizada como um composto nocivo à função renal. Em um estudo publicado recentemente onde foi analisado a frequência de cálculos renais em praticantes de exercício físico do município de Juiz de Fora (Minas Gerais) que utilizavam suplementos alimentares, dentre estes pontua-se que a creatina foi o segundo mais consumido, os autores encontraram uma diferença estatística ao comparar ao grupo que não utilizada destes recursos (MACEDO AS, et al., 2020).

Estudos envolvendo seres humanos são comumente criticados pelo seu poder estatístico e metodologias destoantes. Portanto, a presente revisão de literatura teve como finalidade identificar e discutir, de modo crítico e analítico, os resultados e conclusões longitudinais sobre o tema "creatina e disfunção renal", em pesquisas feitas com seres humanos, no decorrer dos últimos anos.

\section{REVISÃO BIBILIOGRÁFICA}

\section{Qualidade de vida}

Considerando que a qualidade de vida de indivíduos portadores de doença renal crônica não é satisfatória, além dos aspectos biopssicossocias destes pacientes estarem prejudicados (SILVA SA, et al., 2021), a investigação de potenciais efeitos deletérios do uso de creatina para este órgão em específico permanece até hoje após estudos apontarem alguns achados inconclusivos.

Dentre os estudos envolvendo seres humanos, associaram o consumo de creatina à sintomatologia de fadiga, dispneia e perda de peso em um atleta asmático com consumo de (10g/dia por 3 meses). Foram verificados valores laboratoriais normais de clearance de creatinina, potássio, sódio e amônia e valor sérico de creatinina $1,7 \mathrm{mg} / \mathrm{dl}$. Diante desse contexto, cessou-se a suplementação com creatina e iniciou-se o tratamento com $\beta$-agonistas e esteroides, levando à diminuição da creatinina para $1,3 \mathrm{mg} / \mathrm{dL}$ e redução dos sintomas (KUEHL L, et al., 1998; KREIDER RB, et al., 2017), além do resultado falso positivo de associação da creatina com o quadro clínico que se dá pela excreção de creatinina ser suscetível à variação de massa muscular, suplementações e modo de treino físico (KREIDER RB, et al., 2017).

Em estudos conduzidos por Marini ACB e Pimentel GD (2020), foi possível observar a melhora na qualidade de vida de pacientes submetidos a hemodiálise a partir de suplementação de $20 \mathrm{~g}$ de creatina/dia. O estudo se baseia no processo de sarcopenia, síndrome caracterizada pela perda de musculatura esquelética, ocorrido naturalmente em pacientes em tratamento de hemodiálise, além da estimulação neuromuscular, no qual, conseguramu manter percentual de atividade quando associado a suplementação com creatina.

Os dados encontrados por Vieira MO e Salomón ALR (2021) demonstram efetividade da adição de creatina por suplementação oral auxiliando em processos de senecencia, tais como sarcopenia e cognicção. Tais dados são importantes, visto que são esperados um "boom" de pessoas idosas, acarretando na inversão da pirâmide etária, sendo necessário uma atenção maior a estes pacientes. A composição de aminoácidos presentes na creatina tem ação sobre músculos, evitando sua degradação, além de apresentar resultados frente a fadiga associado a exercícios físicos de baixa intensidade. Ainda, apresenta ação neuroprotetora, beneficiando principalmente energia cerebral da população idosa.

\section{Alterações fisiológicas}

Associações do aumento da pressão arterial sanguínea e das concentrações séricas de creatinina (2,3 $\mathrm{mg} / \mathrm{dL}$ ) de um indivíduo de 25 anos ao uso da creatina como recurso ergogênico, demonstrando o desenvolvimento de injúria tubular focal e nefrite intersticial aguda (GUINGAND DL, et al., 2020). Em 2004, o conjunto científico da European Food Safety Authority (EFSA) afirmou que a creatina não era motivo de preocupação quando utilizada em sua forma monohidratada e quando garantida a pureza de sua fonte. 
Todavia, como contra resposta a Agência Francesa de Saúde e Segurança Alimentar (AFSSA) alegou que seu uso não deveria ser encorajado para fins de proteção à qualquer potencial patológico ainda desconhecido (WALLIMANN T, et al., 2017).

Casos clínicos associando injúria renal e creatina foram publicados, como o quadro de paciente jovem com glomerulonefrite membranoproliferativa difusa do tipo I que fazia uso de suplementação com creatina (200g/dia), mas que também fazia uso de esteróide hormonal (metandienona) associado à suplementação (RÉVAI T, et al., 2003). Além dos marcadores conhecidos, é possível citar o biomarcador KIM-1 que é uma glicoproteína transmembrana indetectável no rim saudável, entretanto, é expresso nas células tubulares proximais quando há lesão renal. Essa característica do KIM-1, juntamente com o fato de estar ausente em outras células do corpo, faz com que esse biomarcador seja confiável e especifico para dano tubular renal (VILAR NETO JO, et al., 2020; TEIXEIRA Y, et al., 2020).

\section{Perfil toxicológico}

Como a creatina possui excreção renal, foi levantado a hipótese de que sua suplementação poderia levar a prejuízo da função renal. Todavia, estudos analisaram os níveis de creatina durante o período em que houve suplementação e não foi constatado aumento significativo da creatina sérica ou prejuízos renais em jovens saudáveis (CHILIBECK PD, et al., 2017; LANHERS C, et al., 2017). Existem relatos de aumento na excreção de creatinina urinária e diminuição da produção de volume urinário, porém, acredita-se que a diminuição do débito urinário venha da retenção de líquido e ganho de peso durante as fases iniciais da suplementação. Observou-se que a creatina resulta em ganho de peso e retenção hídrica durante um curto período de tempo (HARGREAVES M e SPRIET LL, 2020; ANTONIO J, et al., 2021).

Em estudo publicado em 2006, os atores relacionaram o quadro de insuficiência renal aguda e nefrite intersticial aguda, diagnosticadas por biopsia renal e exames laboratoriais, em um homem de 24 anos, ao uso de $15 \mathrm{~g}$ de creatina por dia, durante 6 semanas, em que foi observado, que os suplementos consumidos pelo indivíduo, a creatina seria o único, de acordo com a literatura científica, a ter esse potencial nefrotóxico. Apesar dos pesquisadores alegarem que a suplementação com creatina apresenta baixa probabilidade de causar injúria renal, eles não descartaram a possibilidade de configurar um diagnóstico diferencial de insuficiência renal aguda em atletas (THORSTEINSDOTTIR B, et al., 2006).

Em outra investigação, foi proposto pelos atuores, analisar dois grupos de indivíduos, ambos com esclerose lateral amiotrófica. O primeiro grupo fazia uso de $10 \mathrm{~g}$ de creatina por dia, durante 310 dias, e o outro grupo fazia uso de placebo. Diante das observações do estudo, os investigadores quantificaram a creatinina de ambos os grupos via Cromatografia Líquida de Alta Eficiência (CLAE), constatando pequenas alterações nos valores de ureia sérica e um quadro de microalbuminuria (GROENEVELD GJ, et al., 2005).

Poortmans JR, et al. (2005) dosaram a concentração na urina de metilamina e formaldeído antes e depois da suplementação de creatina para analisar a formação de compostos citotóxicos, sendo avaliados 20 homens saudáveis com ingestão de $21 \mathrm{~g}$ por 14 dias. Como resultado, não obtiveram alteração na função renal, quando baseados em clearance de creatinina (Clcrn), creatinina ( $\mathrm{Crn}$ ) e albumina urinária. No entanto, observou-se aumento na concentração de metilamina de 9,2 vezes e formaldeído de 4,5 vezes. Os responsáveis pelo estudo relataram que a vitalidade renal com a creatina é preservada, apesar da formação destes compostos.

Kim HJ, et al. (2011) buscaram evidências experimentais sobre o risco da suplementação com creatina ao organismo. Os autores investigaram a taxa de filtração glomerular por meio da quantificação da Cistatina-C plasmática e da excreção de albumina. Os resultados mostraram valores de função renal dentro da faixa de normalidade e ausência de alteração da permeabilidade da membrana glomerular.

Considerando esta linha de raciocínio, uma revisão publicada por Post A, et al. (2019) também reforçou a segurança deste composto para que utiliza deste recurso por período de cinco dias até cinco anos. Além disso, os autores indicaram que a suplementação com creatina não leva a formação de compostos cancerígenos. 
A suplementação com creatina a longo prazo prejudicaria a função renal em indivíduos em treinamento resistido acompanhado de dieta hiperproteica. Em diversos estudos a função renal estava avaliada por meio da creatinina sérica e sabe-se que fatores influenciam esse parâmetro, como a própria conversão da creatina em creatinina indicar falsamente uma diminuição da função renal. Dessa forma, foi utilizado pelo autor o método Cr-EDTA para verificar com precisão a taxa de filtração glomerular e por meio da técnica mencionada, não foi evidenciado declínio da função renal dos indivíduos estudados (ANDRES S, et al., 2017; LOBO RED, et al., 2021).

Por fim, a segurança do uso de creatina em pacientes que não possuíam qualquer disfunção renal prévia. Souza e Silva A, et al. (2019) apontaram até um benefício para o uso deste suplemento em pacientes com distúrbios neuromusculares e metabólicos, podendo até contribuir para uma melhora da sensibilidade à insulina em pacientes com diabetes tipo 2.

\section{Creatinina e exercício físico}

Atividades que exigem rápidas e intensas contrações musculares durante curto período de tempo, como por exemplo as provas de velocidade do atletismo, dependem dos estoques intramusculares de ATP e fosfocreatina. Estudos apontaram aumento nos estoques intramusculares de creatina e fosfocreatina com suplementação de creatina monohidratada. Entretanto, vale ressaltar que essa reserva e acúmulo possuem limite superior de $160 \mathrm{~g}$ no corpo humano. Logo, atletas com estoques completos de creatina nos músculos não são tão beneficiados com a suplementação. Em contrapartida, pessoas com menor estoque muscular de creatina recebem maior efeito quando suplementados. Dessa maneira, o benefício da creatina consiste em aumentar os estoques musculares para facilitar a produção de ATP e fosfocreatina, retardando o início da fadiga muscular (LANHERS C, et al., 2015, 2017).

A Sociedade Internacional de Nutrição Esportiva relatou que não há evidências de que a suplementação com creatina monohidratada traga efeitos adversos e colaterais em pessoas previamente hígidas, desde que utilizada de forma adequada. Estudo com jovens saudáveis que utilizaram creatina em período de uma a dez semanas não demonstrou efeitos adversos (JAGIM AR, et al., 2018).

Atletas utilizam a creatina como suplemento ergogênico para aumentar o ganho de força e a resistência muscular frente aos esforços realizados durante a prática de exercícios físicos. Esse suplemento vem sendo amplamente estudado no meio científico, principalmente em sua forma "monohidratada", sendo que essa formulação foi beneficamente comprovada por meio de estudos, principalmente em atividades de curta duração e alta intensidade, como levantamento de peso (CHILIBECK PD, et al., 2017; BUTTS J et al., 2018).

De acordo com Davani-Davari D, et al. (2018), atletas que praticam exercício de força que receberam $20 \mathrm{~g}$ de creatina por dia não obtiveram alterações marcantes de creatinina no soro ou urinária, ou até mesmo na taxa de excreção de creatinina ou em sua depuração. Por outro lado, os autores ressaltaram que a creatina pode ser convertida em sarcosina e que essa é capaz de originar outros agentes citotóxicos como a metilamina e consequentemente o formaldeído, mas tal composto não foi correlacionado com os níveis de creatina plasmática.

Nos Estados Unidos pesquisadores recrutaram 98 jogadores hígidos de futebol universitário da National Collegiate Athletic Association para participar do estudo por dois anos, sendo coletado amostras de sangue e urina. Ao todo, 65 indivíduos se ofereceram para participar durante a primeiro ano e cerca de 40 indivíduos se ofereceram para participar do segundo ano do estudo. Amostras de sangue em jejum e urina de 24 horas foram coletadas dos atletas durante o protocolo de treinamento. Ao final, 44 sujeitos foram categorizados como não usuários de creatina, 12 fizeram uso durante os seis primeiros meses, 25 pessoas ingeriram 7 a 12 meses e os que tomaram de 12-21 meses foram 17. Como conclusão central, as amostras sanguíneas e urinárias não revelaram diferenças significativas entre usuários de creatina e não usuários no painel quantitativo de marcadores de sangue e urina avaliados (KREIDER RB et al., 2003).

Em pesquisa realizada por Ostojic SM (2021) utilizou-se dados de 2017-2018 advindos da National Health and Nutrition Examination Survey (NHANES) em que foi analisado o consumo individual de creatina 
(baixa: < 1g/dia; média: 1,00 e 1,99g/dia; alta: $\geq 2,0 \mathrm{~g} /$ dia). Como resultado principal, não foi observado qualquer correlação entre consumir mais creatina e insuficiência renal em adultos norte-americanos.

O próximo estudo a ser citado analisou textos científicos sobre os efeitos na função renal devido a suplementação de creatina para fins esportivos, sendo questionado se indivíduos saudáves suplementados com creatina a longo prazo podem ter deterioção da sua função renal. Como resultado, não foram encontradas alterações em pré e pós avaliações laboratoriais, concluindo que a suplementação com creatina a longo prazo é segura (VEJA J e HUIDOBRO EJP, 2019).

\section{Creatina e mulheres}

O conseguinte estudo em vigência apresentou como pauta a suplementação de creatina e possível alteração na taxa de filtração glomerular avaliada em mulheres na pós-menopausa hígidas. A todo, 24 mulheres com 58 anos ( \pm 3 anos) foram designadas aleatoriamente para receber creatina, sendo que 13 receberam $20 \mathrm{~g} /$ dia por 7 dias, seguidas por dose única de $5 \mathrm{~g} /$ dia durante as 11 semanas seguintes e 11 receberam placebo, além de programa de exercícios supervisionados 3 vezes na semana durante 3 meses para todos. A função renal foi avaliada no início e após 12 semanas, pela dosagem de creatinina, albumina, proteinúria e ureia. Entre o início do experimento e o término, não houve alterações significativas. Concluise assim que a suplementação com creatina não afeta a filtração glomerular em mulheres menopausadas (NEVES M, et al., 2011).

Considerando que portadores de doença renal crônica sofrem de distúrbios que regulam o metabolismo do cálcio, um grupo de pesquisadores investigou se o uso de creatina durante 2 anos alteraria a saúde óssea e a massa muscular de 200 idosas sedentárias portadoras de osteopenia que se encotravam no período pós menopausa (SALES LP, et al., 2019). Como resultado principal, os autores não encontraram benefícios para o uso deste recurso, evidenciando que para colher os benefícios oriundos deste suplemento torna-se necessário a prática de exercício físico periódico.

\section{Creatina e acompanhamento profissional}

A suplementação nutricional com creatina deve ser feita com cuidado e por profissionais habilitados, que tenham conhecimento amplo sobre fisiologia, anatomia, metabolismo e bioquímica, visto que a prescrição de uma terapêutica sem uma causa definida, ou uma boa anamnese realizada pode levar a quadros patológicos indesejados e a quadros mais graves como insuficiência renal e até mesmo a morte. Além, é importante salientar, que a prescrição deve seguir o ritmo do paciente, em um atendimento personalizado, visto que as características e necessidades são únicas (PEDROSA I, et al., 2021).

Dessa forma, não é seguro revelar uma dose indicada, ou terapêutica indicada para cada patologia, visto que a individualidade do paciente deverá ser o ponto de partida para prescrição de toda formulação. Importante ressaltar, que a prescrição de creatina sempre é acompanhada de outros nutraceuticos, no qual devem ser observados para falência renal, sobrecarga cardíaca e metabólica, afetando níveis glicêmicos, insulínicos e outros hormônios de controle homeostático e ainda, é aconselhável que o prescritor faça acompanhamento clínico-laboratorial frequente (JUNIOR SA, et al. 2019; SOARES IF, et al., 2020). A condução de trabalhos de referencial teórico a partir de bases cientificas é de suma importância, sendo necessário para formação e condução de terapêutica, no que compreendemos como tratamento baseado em evidencias cientificas (COELHO, et al. 2020).

\section{CONSIDERAÇÕES FINAIS}

Ao analisar o uso da creatina isoladamente e como único fator desencadeante para a injúria renal, não foram encontradas evidências suficientes que consolidem a associação entre disfunção renal e o uso dessa substância. Alterações, quando encontradas em exames, são prontamente refutadas pelos próprios marcadores citados estarem sujeitos a alterações por motivos diversos e justificáveis. Cabe salientar que a creatina monohidratada como forma de suplemento é segura segundo os órgãos de saúde, quando utilizada da maneira correta. Sendo assim, este suplemento pode ser prescrito, quando necessário, por médicos e nutricionistas para pacientes que objetivem melhora no desempenho esportivo. 


\section{AGRADECIMENTOS}

Os autores agradecem o apoio da Coordenação de Aperfeiçoamento de Pessoal de Nível Superior (CAPES).

\section{REFERÊNCIAS}

1. ANDRES $S$, et al. Creatine and creatine forms intended for sports nutrition. Molecular Nutrition \& Food Research, 2017; 61(6): 1600772.

2. ANTONIO J, et al. Common questions and misconceptions about creatine supplementation: what does the scientific evidence really show? Journal of the International Society of Sports Nutrition, 2021; 18(13): 1-17.

3. BUTTS J, et al. Creatine Use in Sports. Sports Health, 2018; 10(1): 31-34.

4. COELHO NL, et al. Comparative Analysis of Differences and Evolution of Hemorrhoidectomy Techniques. Annual Research \& Review in Biology, 2020; 35(6): 60-67.

5. CHILIBECK PD, et al. Effect of creatine supplementation during resistance training on lean tissue mass and muscular strength in older adults: a meta-analysis. Open Access Journal of Sports Medicine, 2017; 8: 213-226.

6. DAVANI-DAVARI D, et al. Potential Adverse Effects of Creatine Supplement on the Kidney in Athletes and Bodybuilders. Iranian Journal of Kidney Diseases, 2018; 12(5): 253-260.

7. FALCÃO LEM. Saturação de creatina em indivíduos fisicamente ativos: técnica eficaz ou desnecessária? Revista Brasileira de Nutrição Esportiva, 2016; 10(57): 327-334.

8. FLORENTIN AN, et al. Uso do suplemento de creatina em praticantes de atividades físicas: uma revisão integrativa. Revista Eletrônica Acervo Saúde, 2021; 13(2): e5890.

9. GROENEVELD GJ, et al. Few Adverse Effects of Long-Term Creatine Supplementation in a Placebo-Controlled Trial. International Journal of Sports Medicine, 2005; 26(4): 307-313.

10. GUINGAND DL, et al. Risk of Adverse Outcomes in Females Taking Oral Creatine Monohydrate: A Systematic Review and Meta-Analysis. Nutrients, 2020; 12(6): 1780.

11. HARGREAVES M, SPRIET LL. Skeletal Muscle Energy Metabolism during Exercise. Nature Metabolism, 2020; 2(9): 817-828.

12. JAGIM AR, et al. Safety of Creatine Supplementation in Active Adolescents and Youth: A Brief Review. Frontiers in Nutrition, 2021; 5: 1-13.

13. JUNIOR SA, et al. Bases pedagógicas em curso profissionalizante de Farmácia e Laboratório Clínico como apoio na construção profissional do indivíduo. Revista Eletrônica Acervo Saúde, 2019; 25: e649.

14. KIM HJ, et al. Studies on the Safety of Creatine Supplementation. Amino Acids, $2011 ; 40(5): 1409-1418$.

15. KREIDER RB, et al. International Society of Sports Nutrition position stand: safety and efficacy of creatine supplementation in exercise, sport, and medicine. Journal of the International Society of Sports Nutrition, 2017; 14(1): 18.

16. KREIDER RB, et al. Long-Term Creatine Supplementation Does Not Significantly Affect Clinical Markers of Health in Athletes. Molecular and Cellular Biochemistry, 2003; 244(1-2): 95-104.

17. KUEHL K, et al. Renal insufficiency after creatine supplementation in a college football athlete. Medicine and Science in Sports and Exercise, 1998; 30: S235.

18. LANHERS C, et al. Creatine Supplementation and Lower Limb Strength Performance: A Systematic Review and Meta-Analyses. Sports Medicine, 2015; 45(9): 1285-1294.

19. LIMA CLS, et al. Creatin and its supplementation as an ergogenic resource in sports performance and body composition: A literature review. Brazilian Journal of Health Review, 2020; 3(4): 7748-7765.

20. LOBO RED, et al. Drug interaction in cancer patients: an integrative literature review. Brazilian Journal of Development, 2021; 7(3): 32289-32303.

21. MACEDO AS, et al. O uso de suplementos alimentares por praticantes de atividade física no município de Juiz de Fora - MG e análise renal. Revista Eletrônica Acervo Saúde, 2020; 45: e2950.

22. MARINI ACB, PIMENTEL GD. Suplementação com creatina e estimulação elétrica neuromuscular melhora força muscular de membros inferiores e qualidade de vida em homens em hemodiálise. Einstein (São Paulo), 2020; 18(27): eCE5623.

23. NEVES M, et al. Effect of Creatine Supplementation on Measured Glomerular Filtration Rate in Postmenopausal Women. Applied Physiology, Nutrition, and Metabolism = Physiologie Appliquee, Nutrition Et Metabolisme, 2011; 36(3): 419-422.

24. OLIVEIRA LM, et al. Efeitos da suplementação de creatina sobre a composição corporal de praticantes de exercícios físicos: uma revisão de literatura. Revista Brasileira de Nutrição Esportiva, 2017; 11(61): 10-15.

25. OSTOJIC SM. Dietary creatine and kidney function in adult population: NHANES 2017-2018. Food Science \& Nutrition, 2021; 9(4): 2257-2259. 
26. PEDROSA I, et al. Suplementação de creatina. Fundamentos teóricos para o seu consumo no futebol como estratégia ergogênica nutricional. The Brazilian Journal of Soccer Science, 2021; 14(1): 3-19.

27. POORTMANS JR, et al. Effect of Oral Creatine Supplementation on Urinary Methylamine, Formaldehyde, and Formate. Medicine and Science in Sports and Exercise, 2005; 37(10): 1717-1720.

28. POST A, et al. Creatine Is a Conditionally Essential Nutrient in Chronic Kidney Disease: A Hypothesis and Narrative Literature Review. Nutrients, 2019; 11(5): E1044.

29. RÉVAI T, et al. Severe nephrotic syndrome in a young man taking anabolic steroid and creatine long term. Orvosi Hetilap, 2003; 144(49): 2425-2427.

30. SALES LP, et al. Creatine Supplementation $(3 \mathrm{~g} / \mathrm{d})$ and Bone Health in Older Women: A 2-Year, Randomized, Placebo-Controlled Trial. Journal of Gerontology A, 2020; 75(5): 931-938.

31. SILVA SA, et al. Qualidade de vida e aspectos sociodemográficos de doentes renais crônicos. Revista Eletrônica Acervo Saúde, 2021; 13(2): e5475.

32. SOARES IF, et al. A Ação da creatina no desempenho esportivo: uma revisão sistemática. Revista Brasileira de Nutrição Esportiva, 2020; 14(89): 536-542.

33. SOUZA e SILVA A. et al. Effects of Creatine Supplementation on Renal Function: A Systematic Review and MetaAnalysis. Journal of Renal Nutrition: The Official Journal of the Council on Renal Nutrition of the National Kidney Foundation, 2019; 29(6): 480-489.

34. TEIXEIRA Y, et al. Efeitos da Suplementação de Creatina Sobre o Desempenho Físico: Uma revisão integrativa de literatura. Research, Society and Development, 2020; 9(7): e982974947.

35. THORSTEINSDOTTIR B, et al. Acute Renal Failure in a Young Weight Lifter Taking Multiple Food Supplements, Including Creatine Monohydrate. Journal of Renal Nutrition: The Official Journal of the Council on Renal Nutrition of the National Kidney Foundation, 2006; 16(4): 341-345.

36. VEJA J, HUIDOBRO EJP. Efectos en la función renal de la suplementación de creatina con fines deportivos. Revista médica de Chile, 2019; 4(1): 628-633.

37. VIEIRA MO, SALOMÓN ALR. O uso da suplementação hiperproteica e creatina em pacientes idosos paliativos na cognição, funcionalidade e sarcopenia. Saúde Coletiva (Barueri), 2021; 11(65): 6252-6269.

38. VILAR NETO JO, et al. Novel renal biomarkers show that creatine supplementation is safe: a double-blind, placebocontrolled randomized clinical trial. Toxicology Research, 2020; 9(3): 263-270.

39. WALLIMANN T, et al. Intradialytic Creatine Supplementation: A Scientific Rationale for Improving the Health and Quality of Life of Dialysis Patients. Medical Hypotheses, 2017; 99(1): 1-14. 